\title{
The effect of gestational weight gain on perinatal outcomes among Chinese twin gestations based on Institute of Medicine guidelines
}

Dongxin Lin ${ }^{1,2}$, Dazhi Fan ${ }^{1,2}$, Shuzhen $\mathrm{Wu}^{1,2}$, Gengdong Chen ${ }^{1,2}$, Pengsheng Li, ${ }^{1,2}$, Huiting Ma ${ }^{1,2}$, Shaoxin Ye $\mathrm{Y}^{1,2}$, Jiaming Rao ${ }^{1,2}$, Huishan Zhang ${ }^{1,2}$, Meng Zeng ${ }^{2}$, Yan Liu ${ }^{2}$, Xiaoling Guo ${ }^{1,2}$ and Zhengping Liu ${ }^{1,2^{*}}$ (D)

\begin{abstract}
Background: Gestational weight gain (GWG) has implications for perinatal outcomes, the guidelines for maternal weight gain, however, remain understudied among twin pregnancies. This study aimed to assess the associations between perinatal outcomes and GWG among twin pregnancies, based on the US institute of Medicine (IOM) 2009 guidelines.

Methods: A retrospective cohort study of pregnant women with viable twins $\geq 26$ weeks of gestation, was conducted in Foshan, China, during July 2015 and June 2018. Maternal BMI was categorized based on Chinese standard and GWG was categorized as below, within and above the IOM 2009 recommendations. Underweight women were excluded for analysis. Perinatal outcomes were compared among these groups. To assess the independent impact of GWG on the perinatal outcomes, conventional multivariable regression and general estimated equation (GEE) were utilized for maternal outcomes and neonatal outcomes, respectively.
\end{abstract}

Results: A total of 645 mothers with twin pregnancies were included, of whom 15.0, 41.4 and $43.6 \%$ gained weight below, within and above guidelines, respectively. Compared to weight gain within guidelines, inadequate weight gain was associated with increased risks in spontaneous preterm birth < 37 weeks (aOR:3.55; 95\% Cl: 1.73-7.28) and $<35$ weeks (aOR:2.63; 95\% Cl: 1.16-5.97). Women who gained weight above guidelines were more likely to have gestational hypertension disorder (aOR: 2.36; 95\% Cl: 1.32-4.21), pre-eclampsia (aOR: 2.59; 95\% Cl: 1.29-5.21) and have fetuses weighted >90th percentile and less likely to have fetuses weighted $<2500 \mathrm{~g}$ and $<1500 \mathrm{~g}$.

Conclusions: Maintenance of gestational weight gain within the normal range could decrease the risk of adverse perinatal outcomes. However, the causality between pre-eclampsia and gestational weight gain requires further investigations.

Keywords: Twin, Gestational weight gain, Preterm birth, Gestational hypertensive disorder, Pre-eclampsia, Birth weight

\footnotetext{
* Correspondence: liuzphlk81@outlook.com

${ }^{1}$ Foshan Institute of Fetal Medicine, Southern Medical University Affiliated

Maternal \& Child Health Hospital of Foshan, 11 Renminxi Road, Foshan

528000, Guangdong, China

2Department of Obstetrics, Southern Medical University Affiliated Maternal \&

Child Health Hospital of Foshan, Foshan 528000, Guangdong, China
}

(c) The Author(s). 2019 Open Access This article is distributed under the terms of the Creative Commons Attribution 4.0 International License (http://creativecommons.org/licenses/by/4.0/), which permits unrestricted use, distribution, and reproduction in any medium, provided you give appropriate credit to the original author(s) and the source, provide a link to the Creative Commons license, and indicate if changes were made. The Creative Commons Public Domain Dedication waiver (http://creativecommons.org/publicdomain/zero/1.0/) applies to the data made available in this article, unless otherwise stated. 


\section{Background}

Twin gestations, different from singleton gestations, are associated with significant adverse perinatal outcomes, such as fetal growth restriction, intrauterine fetal death, preterm birth and perinatal mortality [1, 2]. To date, many efforts have been developed in identifying factors which may jeopardize maternal and fetal health.

As reported in previous studies, gestational weight gain (GWG) has implications for the health of mother and child. Women with insufficient weight gain during gestation were observed to be associated with lower birth weight whereas those with excessive weight gain were associated with macrosomia, postpartum weight retention and offspring obesity [3-6]. The demand for nutrition supply, theoretically, should be higher for twin pregnancies than singletons [7]. Guidelines of GWG for singleton pregnancies were well established, whereas those for twin pregnancies were undeveloped. In 2009, the US institute of Medicine (IOM) released revised recommendations on maternal GWG for twin gestations [8]. These recommendations represented the interquartile range of weight gain among women who deliver twins with a mean weight of $\geq 2500 \mathrm{~g}$ at term (37-42 weeks of gestation) and were referred as provisional.

One of the most important questions comes to their validity since there are a significant proportion of twins born before 37 weeks of gestation and other perinatal outcomes to be assessed. Multiple researches from western countries had attempted to examine these guidelines on various perinatal outcomes among twin pregnancies, however, these studies yielded inconsistent results possibly due to several limitations, such as small sample size, exclusion of monochorionic or pre-term pregnancies [9-13]. Besides, as the Chinese adult body mass index (BMI) category standards for normal weight, overweight and obesity were lower than WHO standards, it is not clear whether these guidelines could apply to Chinese women with twin gestations.

In the view of the ever-increasing incidence of twin births in China [14], it is imperative to provide more evidence regarding this issue, in order to optimize maternal and fetal outcomes. Therefore, this study aimed to elucidate the association between maternal GWG and a series of perinatal outcomes, based on 2009 IOM recommendations.

\section{Methods}

\section{Study design}

This retrospective cohort study was conducted between July 2015 and June 2018, in a tertiary maternal and child health hospital in Foshan, China. All obstetric records of eligible subjects were systematically reviewed, and relevant data were extracted by pre-designed standardized forms. The study was approved by the ethics committee of Southern Medical University Affiliated Maternal \& Child Health Hospital of Foshan (ethics approval number: FSFY-20180903).

\section{Inclusion and exclusion criteria}

All pregnant women who aged between 18 and 55 years, had first antenatal visit in the first trimester and gave birth to viable twins at gestational age of $\geq 26$ weeks were eligible for inclusion. Exclusion criteria included congenital anomalies, twin-to-twin transfusion (TTTS), monoamniotic twins, intrauterine death. Women were also excluded if there is no available information on maternal height or weight at the first prenatal visit or delivery.

\section{Information collection}

Demographic and obstetric information were collected including maternal age, educational level, chronic hypertension, pre-existing diabetes mellitus, parity, obstetric history, use of assisted reproductive technology (ART), cesarean section, chorionicity, gestational age at delivery, maternal BMI and maternal weight gain at delivery.

Gestational age at delivery was calculated by the last menstrual period and confirmed by early sonography. Since pre-gestational weight was not available in medical chart, we used the measured weight in the first antenatal visit before 14 weeks instead to determine maternal BMI and gestational weight gain, like prior studies [15-17]. Maternal BMI, calculated by dividing their weight (in kilograms) by height (in meters squared), was categorized as underweight (BMI $<18.5 \mathrm{~kg} /$ $\left.\mathrm{m}^{2}\right)$, normal weight $\left(18.5-23.99 \mathrm{~kg} / \mathrm{m}^{2}\right)$, overweight $(24-$ $\left.27.99 \mathrm{~kg} / \mathrm{m}^{2}\right)$ and obesity $\left(\geq 28 \mathrm{~kg} / \mathrm{m}^{2}\right)$ according to the standard of the Working Group on Obesity in China [18]. Gestational weight gain (GWG) was assessed as previous studies [13, 19-22]. The rates of recommended weight gain, obtained by dividing the recommended weight gain by 37 weeks, were as follows: $0.459-0.676 \mathrm{~kg}$ per week for normal weight; $0.378-0.622 \mathrm{~kg}$ per week for overweight and $0.297-0.514 \mathrm{~kg}$ per week for obesity. GWG of subjects, calculated by dividing the total weight gain by gestational weeks from the initial antenatal visit, was compared against the rate of recommended weight gain and define as below, within and above the IOM guidelines. Due to no recommendations for underweight pregnant women with twin gestations, those with $\mathrm{BMI}<18.5 \mathrm{~kg} / \mathrm{m}^{2}$ were not included for analysis.

\section{Outcomes of interest}

The primary outcome of the current study were preterm birth (PTB, including spontaneous and iatrogenic PTB) $<37,<35$ and $<32$ weeks and different phenotypes of spontaneous PTB. Other outcomes included gestational hypertensive disorder, gestational hypertension, pre- 
eclampsia, anemia, preterm premature rupture of membranes (PPROM), small for gestational age (SGA) $<10$ th percentile, large for gestational age (LGA) $>90$ th percentile, low birth weight (LBW) $<2500 \mathrm{~g}$ and $<1500 \mathrm{~g}$, neonatal intensive care unit (NICU) admission and neonatal respiratory distress syndrome (NRDS). Incidence of gestational diabetes mellitus (GDM) was reported but not evaluated as an outcome in this study since nutritional counseling and dietary adjustment may occur and have a consequent impact on GWG after the diagnosis of GDM. Gestational hypertension was defined as a new development of a blood pressure of $\geq 140 / 90 \mathrm{mmHg}$ after 20 weeks' gestation without proteinuria. A diagnosis of pre-eclampsia (PE) was made when a blood pressure of $\geq 140 / 90 \mathrm{mmHg}$ and proteinuria of $\geq 300 \mathrm{mg} / 24 \mathrm{~h}$ were simultaneously found. Gestational hypertensive disorder was defined when at least one of the following complications occurred: gestational hypertension, preeclampsia and eclampsia [23]. Gestational anemia was diagnosed if the hemoglobin concentration was below $11.0 \mathrm{~g} / \mathrm{dl}$ before delivery. SGA and LGA were defined when the birth weight was below the 10th percentile and above the 90th percentile for gestation age and sex based on twin birth weight curves in Chinese twins, respectively [24, 25].

\section{Statistical analysis}

All statistical analyses were performed using Stata, version 13.1. The baseline characteristics and outcomes were compared between three GWG categories. Continuous variables with approximately gaussian distribution were presented as mean $\pm \mathrm{SD}$ and analyzed by analysis of variance (ANOVA). Categorical variables were presented as frequency and accompanying percentage and analyzed by chi-square test or Fisher's exact test, when appropriate. We applied multivariable logistic regression models to estimate the independent influence of maternal weight gain on perinatal outcomes. Weight gain within IOM guidelines served as the reference. For neonatal outcomes, logistic models with general estimated equations (GEE) were used in order to address the correlation between fetuses in a paired set. A priori determined variables including maternal age, maternal BMI classification, chorionicity as well as gestational age at delivery. All the effect estimates were reported as adjusted odds ratios (aOR) and accompanying 95\% confidence intervals $(\mathrm{CI})$ and presented graphically as forest plots. All $P$-values were two tailed, and $P$-values $<0.05$ were considered as statistical significance.

\section{Results}

There were 1308 women with twin pregnancy admitted to maternal and child health hospital in Foshan, China, during the study period. Six-hundred and forty-five women with 1290 infants were finally included for analysis after excluding records of pregnancies which did not meet our inclusion criteria $(n=552)$, and underweight women $(n=111)$ (Fig. 1$)$.

\section{Baseline characteristics}

Characteristics of included twin pregnancies were presented in Table 1. Of included women, 15.04, 41.40 and $43.57 \%$ were below, within and above the recommended weight gain, respectively. The mean maternal age of eligible participants was $32.1 \pm 4.3$ years, and a significant

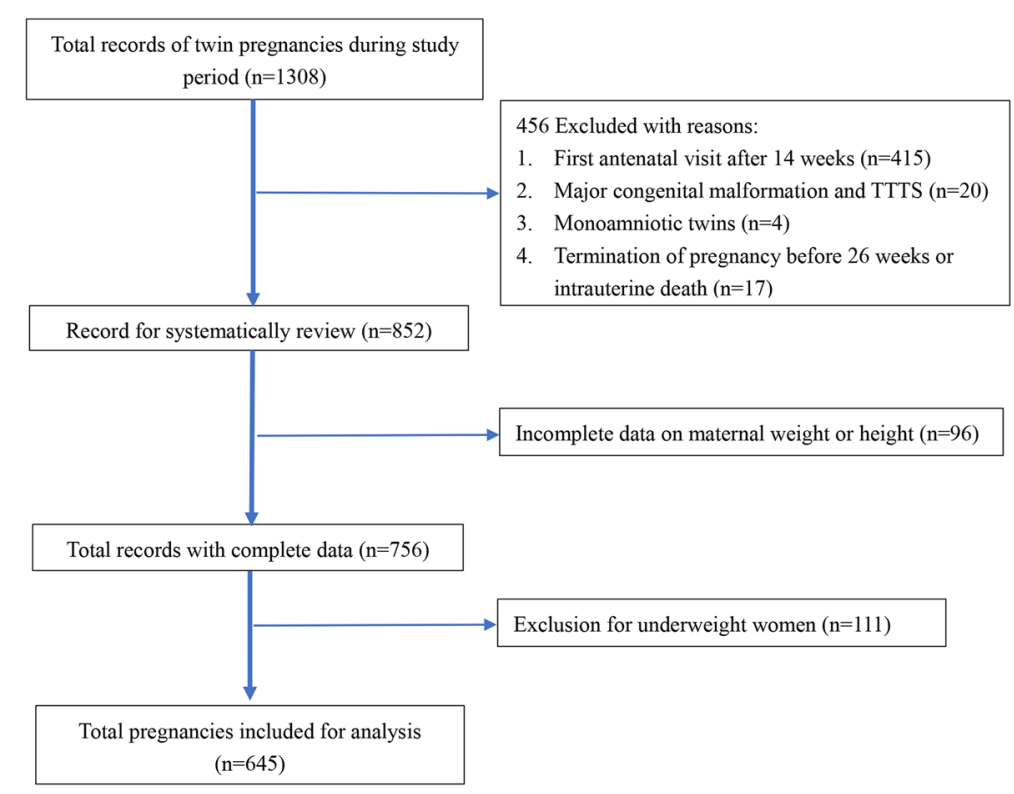

Fig. 1 Flowchart of selection of eligible subjects 
Table 1 Characteristics of twin pregnancies by maternal pre-pregnancy BMl classification and by gestational weight gain according to Institute of Medicine Guidelines

\begin{tabular}{|c|c|c|c|c|c|}
\hline Characteristics & $\begin{array}{l}\text { All participants } \\
(n=645)\end{array}$ & $\begin{array}{l}\text { Weight gain within } \\
\text { IOM guideline } \\
(n=267)\end{array}$ & $\begin{array}{l}\text { Weight gain below } \\
\text { IOM guideline } \\
(n=97)\end{array}$ & $\begin{array}{l}\text { Weight gain above } \\
\text { IOM guideline } \\
(n=281)\end{array}$ & $P$-value \\
\hline Maternal age, year & $32.1 \pm 4.3$ & $32.7 \pm 4.4$ & $32.0 \pm 4.3$ & $31.5 \pm 4.2$ & 0.007 \\
\hline \multicolumn{6}{|l|}{ Maternal BMI classification } \\
\hline Normal & $475(73.64)$ & $190(71.16)$ & $69(71.13)$ & $216(76.87)$ & \multirow[t]{3}{*}{0.506} \\
\hline Overweight & $130(20.16)$ & $58(21.72)$ & $23(23.71)$ & $49(17.44)$ & \\
\hline Obesity & $40(6.2)$ & $19(7.12)$ & $5(5.15)$ & $16(5.69)$ & \\
\hline Nulliparity & $415(64.34)$ & $159(59.55)$ & $66(68.04)$ & $190(67.62)$ & 0.102 \\
\hline Chorionic hypertension & $2(0.31)$ & $1(0.37)$ & $1(1.03)$ & $0(0)$ & 0.147 \\
\hline Pre-existing diabetes mellitus & $11(1.78)$ & $4(1.57)$ & $4(4.26)$ & $3(1.12)$ & 0.131 \\
\hline College degree $^{a}$ & $283(49.13)$ & $126(53.85)$ & $44(51.76)$ & $113(43.97)$ & 0.080 \\
\hline Use of ART & $486(75.35)$ & $203(76.03)$ & $74(76.29)$ & $209(74.38)$ & 0.880 \\
\hline Prior cesarean section & $99(15.35)$ & $39(14.61)$ & $13(13.4)$ & $47(16.73)$ & 0.668 \\
\hline Prior spontaneous abortion & $131(20.31)$ & $65(24.34)$ & $15(15.46)$ & $51(18.15)$ & 0.086 \\
\hline Prior induced abortion & $137(21.24)$ & $58(21.72)$ & $21(21.65)$ & $58(20.64)$ & 0.948 \\
\hline MCDA twin gestation & $97(15.04)$ & $35(13.11)$ & $14(14.43)$ & $48(17.08)$ & 0.422 \\
\hline Gestational diabetes mellitus & $154(23.88)$ & $69(25.84)$ & $40(41.24)$ & $45(16.01)$ & $<0.001$ \\
\hline Cesarean section & $635(98.45)$ & $263(98.50)$ & $96(98.97)$ & $276(98.22)$ & 1.000 \\
\hline
\end{tabular}

amissing data on 69 cases

difference was found between women with weight gain below, within and above IOM guidelines $(P=0.007)$. Approximately $15 \%$ of included pregnancies were monochorionic-diamniotic. There were no significant differences between the three groups for maternal BMI classification, nulliparity, chorionic hypertension, preexisting diabetes mellitus, college degree, use of ART, cesarean section and prior cesarean section, spontaneous abortion and induced abortion. The incidence of gestational diabetes mellitus was significantly different across different GWG categories, highest among women with inadequate weight gain compared to other groups $(P<0.001)$.

\section{Maternal outcomes according to different IOM classification of GWG}

The maternal outcomes were compared among women with inadequate, adequate and excessive GWG and presented in Table 2. Both gestational hypertensive disorder and pre-eclampsia, were significantly different among these groups $(P=0.004$ and $P=0.006$, respectively). On the contrary, gestational hypertension did not differ among these study groups $(P=0.643)$. None of the included patients had eclampsia. A higher rate of preterm birth < 35 weeks was found among women with inadequate weight gain (24.74\%) compared to those with adequate $(18.35 \%)$ and excessive weight gain $(12.81 \%)(P=$ 0.018 ). No difference was observed in preterm birth <
37 and $<32$ weeks ( $P=0.422$ and $P=0.692$, respectively). When we analyzed spontaneous preterm birth, we found increases in spontaneous $\mathrm{PTB}<37$ and $<35$ weeks in inadequate weight gain group compared to other groups ( $P<0.001$ and $P=0.001$, respectively). The incidence of spontaneous $\mathrm{PTB}<32$ weeks was highest in inadequate weight gain group although the difference was near to statistical significance $(P=0.056)$. There were no significant differences in gestational anemia and PPROM between the three groups (all $P$-value $>0.05$ ).

After we controlled for potential confounders in multivariable logistic regression models, as shown in Fig. 2, neither inadequate nor excessive GWG was associated with preterm birth $<37,<35$ and $<32$ weeks. Nevertheless, higher risks of spontaneous PTB $<37$ and $<35$ weeks were observed among women who gained weight below the recommendations compared to normal weight gain women (adjusted OR of 3.55 [95\% CI: 1.73-7.28] and 2.63 [95\% CI: 1.16-5.97] for spontaneous $\mathrm{PTB}<37$ and $<35$ weeks, respectively). Women with inadequate weight gain also had higher odds of gestational anemia (adjusted OR: 1.65; 95\% CI: 1.03-2.64). Women who gained weight above IOM guidelines had $136 \%$ higher odds of gestational hypertensive disorder (95\% CI: 1.32-4.21) and 159\% higher odds of pre-eclampsia (95\% CI: 1.29-5.21) compared to women who gained weight within the guidelines (Fig. 2). 
Table 2 Maternal outcomes by maternal pre-pregnancy BMI classification and by gestational weight gain according to Institute of Medicine Guidelines

\begin{tabular}{|c|c|c|c|c|c|}
\hline Characteristics & $\begin{array}{l}\text { All participants } \\
(n=645)\end{array}$ & $\begin{array}{l}\text { Weight gain within } \\
\text { IOM guideline } \\
(n=267)\end{array}$ & $\begin{array}{l}\text { Weight gain below } \\
\text { IOM guideline } \\
(n=97)\end{array}$ & $\begin{array}{l}\text { Weight gain above } \\
\text { IOM guideline } \\
(n=281)\end{array}$ & $P$-value \\
\hline Gestational hypertensive disorder & $65(10.08)$ & $19(7.12)$ & $5(5.15)$ & $41(14.59)$ & 0.004 \\
\hline Gestational hypertension & $20(3.1)$ & $7(2.62)$ & $2(2.06)$ & $11(3.91)$ & 0.643 \\
\hline Pre-eclampsia & $45(6.98)$ & $12(4.49)$ & $3(3.09)$ & $30(10.68)$ & 0.006 \\
\hline Gestational anemia & $273(42.33)$ & $101(37.83)$ & $49(50.52)$ & $123(43.77)$ & 0.077 \\
\hline Preterm premature rupture of membrane & $76(11.78)$ & $37(13.86)$ & $12(12.37)$ & $27(9.61)$ & 0.299 \\
\hline Preterm birth < 37 weeks & $472(73.18)$ & 189 (70.79) & $75(77.32)$ & $208(74.02)$ & 0.422 \\
\hline Preterm birth $<35$ weeks & $109(16.9)$ & $49(18.35)$ & $24(24.74)$ & $36(12.81)$ & 0.018 \\
\hline Preterm birth $<32$ weeks & $27(4.19)$ & $12(4.49)$ & $5(5.15)$ & $10(3.56)$ & 0.692 \\
\hline Spontaneous Preterm birth < 37 weeks & $50(7.75)$ & $17(6.37)$ & $18(18.56)$ & $15(5.34)$ & $<0.001$ \\
\hline Spontaneous Preterm birth < 35 weeks & $34(5.27)$ & $14(5.24)$ & $12(12.37)$ & $8(2.85)$ & 0.001 \\
\hline Spontaneous Preterm birth < 32 weeks & $13(2.02)$ & $5(1.87)$ & $5(5.15)$ & $3(1.07)$ & 0.056 \\
\hline
\end{tabular}

\section{Neonatal outcomes according to different IOM classification of GWG}

The current study included a total of 1290 fetuses in the analysis. Results of univariable analysis were shown in Table 3. Statistically significant differences were found in birth weight $<2500 \mathrm{~g}$ and $<1500 \mathrm{~g}$, LGA, NICU admission and NRDS between women who gain weight under, within and above recommended GWG (all $P$-value $<0.05$ ).
Results of general estimated equations reported no significant associations between inadequate weight gain and adverse outcomes in our study after adjusting for maternal age, maternal BMI classification, chorionicity and gestational age at delivery. Nevertheless, excessive weight gain increased the risk of LGA (adjusted OR: 2.48; 95\% CI: 1.17-5.22) and also decreased the risks of birth weight $<2500 \mathrm{~g}$ (adjusted

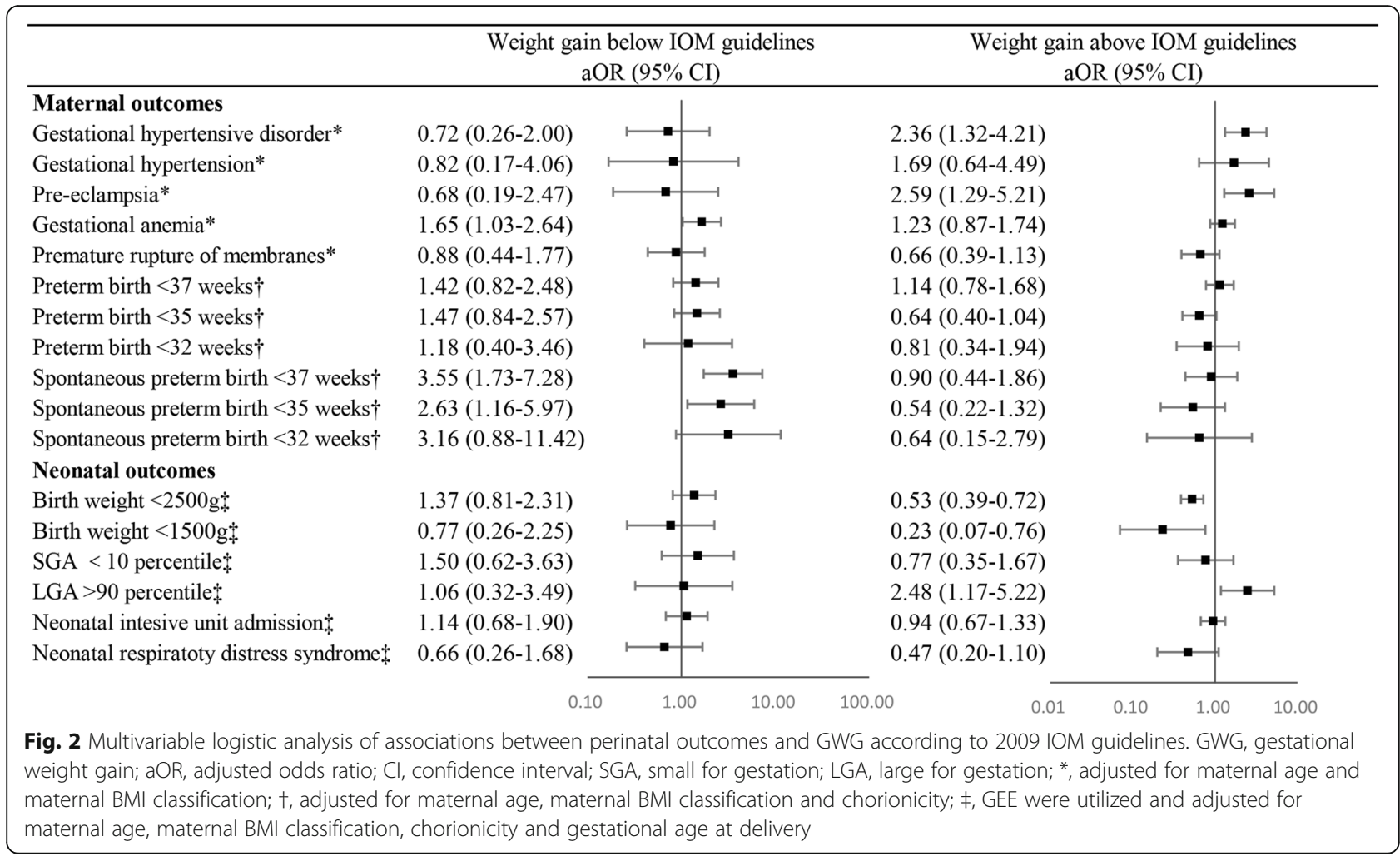


Table 3 Neonatal outcomes by maternal pre-pregnancy BMI classification and by gestational weight gain according to Institute of Medicine Guidelines

\begin{tabular}{|c|c|c|c|c|c|}
\hline Characteristics & $\begin{array}{l}\text { All fetuses } \\
(n=1290)\end{array}$ & $\begin{array}{l}\text { Weight gain within } \\
\text { IOM guideline } \\
(n=534)\end{array}$ & $\begin{array}{l}\text { Weight gain below } \\
\text { IOM guideline } \\
(n=194)\end{array}$ & $\begin{array}{l}\text { Weight gain above } \\
\text { IOM guideline } \\
(n=562)\end{array}$ & $P$-value \\
\hline Birth weight < $2500 \mathrm{~g}$ & $823(63.8)$ & $360(67.42)$ & $149(76.8)$ & $314(55.87)$ & 0.003 \\
\hline Birth weight < $1500 \mathrm{~g}$ & $58(4.5)$ & $32(5.99)$ & $11(5.67)$ & $15(2.67)$ & 0.004 \\
\hline Small for gestational age & $69(5.35)$ & $29(5.43)$ & $16(8.25)$ & $24(4.27)$ & 0.109 \\
\hline Large for gestational age & $71(5.5)$ & $19(3.56)$ & $7(3.61)$ & $45(8.01)$ & 0.003 \\
\hline Neonatal intensive unit admission & $490(37.98)$ & $206(38.58)$ & $88(45.36)$ & $196(34.88)$ & 0.004 \\
\hline Neonatal respiratory distress syndrome & $79(6.12)$ & $44(8.24)$ & $13(6.70)$ & $22(3.91)$ & 0.009 \\
\hline
\end{tabular}

OR: $0.53 ; 95 \% \mathrm{CI}: 0.39-0.72$ ) and $<1500 \mathrm{~g}$ (adjusted OR: 0.23 ; 95\% CI: $0.07-0.76)$. (Fig. 2 ).

\section{Discussion}

This study sought to evaluate the associations between gestational weight gain and perinatal outcomes among Chinese twin gestations, according to 2009 IOM guidelines. We found that, on one hand, weight gain below the IOM guidelines was associated with significant increases in spontaneous preterm birth $<37$ and $<35$ weeks as well as anemia; on the other hand, weight gain above the guidelines was associated with higher rates of gestational hypertensive disorder, pre-eclampsia and fetal macrosomia and lower rates of birth weight $<2500 \mathrm{~g}$ and $<1500 \mathrm{~g}$.

Preterm birth, the primary outcomes in the current study, predominates in adverse outcomes among twin pregnancies. Identifying indicators of PTB would be beneficial for optimization of neonatal outcomes. We found none of the association between maternal weight gain and $\mathrm{PTB}<37,<35$ or $<32$ weeks. The increased risks of spontaneous PTB $<37$ and $<35$ weeks, nevertheless, were found among women with weight gain below the recommended level, compared to those with weight gain within the recommended range. These results were similar with the previous findings of González-Quintero et al. They reported women with twin gestations who had weight gain at or above guidelines, could had a significantly lower rate of spontaneous preterm birth than those who had weight gain below the guidelines [21]. Rather than combining women with weight gain at or above the guidelines as a reference, we did only use normal weight gain as the reference, compared to previous studies [21, 22]. Thus, our results may provide more detailed information on the association between maternal weight gain and spontaneous preterm birth. Algeri et al. [11] reported that excessive GWG is associated with higher risk of spontaneous preterm delivery $<37$ weeks as well. This finding is less valid due to the limited number of women with inadequate weight gain. The mechanism how maternal weight gain influence the spontaneous preterm birth is uncertain. Similar incidence of PPROM was observed between three GWG categories in our results, which was supported by a former study [9]. In addition, an increased risk of gestational anemia was observed among women with inadequate weight gain. Recently Pécheux et al. [26] speculated that strengthening uterine contractions may occur by a surge of stress hormones, induced by placenta dysfunction in the anemia status. Based on our results, we stressed the necessity of sufficient weight gain among women with twin gestations.

The association between weight gain above recommended GWG and gestational hypertensive disorder reported in our study was endorsed by those of previous studies [10, 11, 27]. Interestingly, when gestational hypertension and pre-eclampsia were analyzed separately, we found an association between excessive weight gain and pre-eclampsia but not gestational hypertension. Existing evidence was controversial on the correlation between maternal weight gain and these vascular complications during twin pregnancy. Some studies reported nonsignificant difference of pre-eclampsia among different GWG categories [9, 12, 28]. The study of Lal et al. [20] showed that the association between preeclampsia and excessive GWG only found in the normal-weight/ underweight group but not in overweight and obese groups. The conflicting results, which could be due to the heterogeneity of the study population and sample size, made it difficult to draw a conclusion on whether these weight gain thresholds may be beneficial in decreasing the risk of these complications. Kosinska-Kaczynska et al. [9] suggested that IOM guidelines could be unsuitable for analyzing pre-eclampsia among twin pregnancies, as they found no overlaps between the GWG ratio range associated with pre-eclampsia and specific IOM-recommended GWG value. Our results may imply the reverse causality between excessive weight gain and pre-eclampsia, since women who have pre-eclampsia develop edema more frequently than those who solely have gestational hypertension. Further prospective studies considering edema as a covariate are warranted to 
elucidate the causality between weight gain and pregnancy-related hypertensive disorder.

A few of previous studies evaluated the association between maternal weight gain and birth weight without including the length of gestation or chorionicity as confounders [20, 21, 27-29]. We thought that these variables play significant roles in fetal growth among twins thus we adjusted these confounders for neonatal outcomes. We found no associations between weight gain below IOM guidelines and neonatal outcomes although higher rates of birth weight $<2500 \mathrm{~g}$ and SGA were observed in the inadequate weight gain group. In this study, maternal BMI was categorized based on Chinese adult standard, different from those in previous studies conducted in western countries $[9,13,21,22]$. These results raised a question whether the lower limit of IOM recommended weight gain has enough sensitivity to detect the SGA twins among Chinese pregnant women, which deserves further study. Alternatively, the lack of significant association could be partly attributed to the smaller number of women gaining weight inadequately than other groups. Large studies suggested that GWG below the IOM recommendations was associated with an increased risk of SGA twins [27, 29]. On the opposite, we found that weight gain above the recommended GWG was associated with a higher risk of LGA, which is consistent with the previous finding of Ozcan et al. [27]. In addition, this GWG category also decreased the risk of birth weight $<2500 \mathrm{~g}$ and $<1500 \mathrm{~g}$.

As gestational weight gain is a satisfying index for evaluating maternal nutrition and a modifiable factor during pregnancy, our results are of clinical significance for patients and clinicians to achieve improved pregnancy outcomes among twin gestations. IOM recommendations could provide a good reference in managing weight gain for Chinese women with twin pregnancies, despite of difference in BMI category between Chinese standard and WHO standard. Furthermore, an intervention on maternal nutrition and weight gain could help to reduce the risk of the above-mentioned adverse outcomes.

Since the 2009 IOM recommendations are for the general twins, we included both monochorionic diamniotic and dichorionic diamniotic twins. Therefore, our study possesses more profound significance than those which only included dichorionic twins [30,31] or did not have information on chorionicity $[27,29]$. In addition, different from majority of prior studies $[10,16,20,28]$, one merit of this study was to apply GEE models to assess neonatal outcomes, which could yield more robust and valid effect estimates and confidence intervals with the correlation in a twin set being controlled. Nevertheless, we also acknowledged some limitations in our study. Firstly, the inherent potential for bias unable to be avoided in the retrospective design may impede the interpretation of the causal relationship between maternal weight gain and pregnancy outcomes. Secondly, due to the limited number in twin pregnancies with weight gain below recommended GWG group, some outcomes need more assessment in further studies. Thirdly, since prepregnancy weight was not available in the medical charts, we used the measured weight at the first prenatal visit before 14 weeks to calculate the maternal BMI and maternal weight gain. This value has some limitations, despite its satisfying correlation with pre-pregnancy weight [32].

\section{Conclusions}

Weight gain below the provisional guidelines for twins is associated twin spontaneous preterm birth while weight gain above the guidelines is associated with gestational hypertensive disorder, pre-eclampsia and LGA. Further prospective research is warranted to confirm the causality of these associations.

\section{Abbreviations \\ ANOVA: Analysis of variance; aOR: adjusted odds ratio; Cl: Confidence interval; ART: Assisted reproductive technology; BMI: Body mass index; GDM: Gestational diabetes mellitus; GEE: General estimated equation; GWG: Gestational weight gain; IOM: Institute of Medicine; LBW: Low birth weight; NICU: Neonatal intensive care unit; NRDS: Neonatal respiratory distress syndrome; PPROM: Preterm premature rupture of membranes; PTB: Preterm birth; SGA: Small for gestational age; TTS: Twin-to-twin transfusion}

\section{Acknowledgements}

We would like to thank Yuyi Gao and Diping Wu in data collection.

\section{Authors' contributions}

DXL and SZW contributed to study conception and design. SXY, JMR and HSZ examined the data integrity and accuracy. DXL and DZF performed data analysis. GDC and PSL provided statistical advices. MZ and YL contributed to result interpretation. DXL drafted the manuscript. HTM revised the manuscript. XLG and ZPL provided helpful suggestions for manuscript revision. All the author read and approved the final manuscript.

Funding

Not applicable.

\section{Availability of data and materials}

The datasets used or analyzed in current study are available from the corresponding author on reasonable requests.

\section{Ethics approval and consent to participate}

This study was approved by the ethics committee of Southern Medical University Affiliated Maternal \& Child Health Hospital of Foshan (ethics approval number: FSFY-20180903). Due to the respective nature of current study, the consent from each subject were waived. Nevertheless, the private information was well protected during the study.

\section{Consent for publication}

Not applicable.

Competing interests

The authors declare that they have no competing interest. 
Received: 26 March 2019 Accepted: 15 July 2019

Published online: 24 July 2019

\section{References}

1. Hiersch L, Okby R, Freeman H, Rosen H, Nevo O, Barrett J, Melamed N. Differences in fetal growth patterns between twins and singletons. J Matern Fetal Neonatal Med. 2018:1-201.

2. Walker AR, Waites BT, Caughey AB. Twins versus singleton pregnancies: outcomes in small for gestational age late preterm deliveries. J Matern Fetal Neonatal Med. 2018:1-6

3. Siega-Riz AM, Viswanathan M, Moos MK, Deierlein A, Mumford S, Knaack J Thieda P, Lux $\sqcup$, Lohr KN. A systematic review of outcomes of maternal weight gain according to the Institute of Medicine recommendations: birthweight, fetal growth, and postpartum weight retention. Am J Obstet Gynecol. 2009;201(4):339.e331-14.

4. Goldstein RF, Abell SK, Ranasinha S, Misso M, Boyle JA, Black MH, Li N, Hu G, Corrado F, Rode L, et al. Association of Gestational Weight Gain with Maternal and Infant Outcomes: a systematic review and meta-analysis. Jama. 2017;317(21):2207-25.

5. Zhang W, Niu F, Ren X. Association of maternal pre-pregnancy body mass index and gestational weight gain with Chinese infant growth. J Paediatr Child Health. 2018.

6. Kominiarek MA, Peaceman AM. Gestational weight gain. Am J Obstet Gynecol. 2017;217(6):642-51.

7. Leese B, Jomeen J, Denton J. Appropriate maternal weight gain in singleton and twin pregnancies: what is the evidence? Hum Fertil (Camb). 2012;15(4):194-9.

8. Institute of M, National Research Council Committee to Reexamine IOMPWG. The National Academies Collection: Reports funded by National Institutes of Health. In: Rasmussen KM, Yaktine AL, editors. Weight Gain During Pregnancy: Reexamining the Guidelines. Washington (DC): National Academies Press (US) National Academy of Sciences; 2009.

9. Kosinska-Kaczynska K, Szymusik I, Kaczynski B, Wielgos M. Observational study of associations between gestational weight gain and perinatal outcomes in dichorionic twin pregnancies. Int J Gynaecol Obstet. 2017; 138(1):94-9.

10. Gavard JA, Artal R. Gestational weight gain and maternal and neonatal outcomes in term twin pregnancies in obese women. Twin Res Hum Genet. 2014:17(2):127-33

11. Algeri P, Pelizzoni F, Bernasconi DP, Russo F, Incerti M, Cozzolino S, Mastrolia SA, Vergani P. Influence of weight gain, according to Institute of Medicine 2009 recommendation, on spontaneous preterm delivery in twin pregnancies. BMC Pregnancy Childbirth. 2018;18(1):6.

12. Fox NS, Saltzman DH, Kurtz H, Rebarber A. Excessive weight gain in term twin pregnancies: examining the 2009 Institute of Medicine definitions. Obstet Gynecol. 2011;118(5):1000-4.

13. Lutsiv O, Hulman A, Woolcott C, Beyene J, Giglia L, Armson BA, Dodds L, Neupane B, McDonald SD. Examining the provisional guidelines for weight gain in twin pregnancies: a retrospective cohort study. BMC Pregnancy Childbirth. 2017:17(1):330

14. Lu X, Zhang J, Liu Y, Wang T, Lu Y, Li Z. Epidemiology of twin births in Southeast China: 1993-2005. Twin Res Hum Genet. 2013:16(2):608-13.

15. Pettit KE, Lacoursiere DY, Schrimmer DB, Alblewi H, Moore TR, Ramos GA. The association of inadequate mid-pregnancy weight gain and preterm birth in twin pregnancies. J Perinatol. 2015;35(2):85-9.

16. Pettit KE, Lacoursiere DY, Schrimmer DB, Alblewi $H$, Moore TR, Ramos GA. Maternal and neonatal outcomes in women with twin pregnancies with excessive gestational weight gain. J Matern Fetal Neonatal Med. 2016;29(13):2182-5

17. Lutsiv O. Examining the provisional guidelines for weight gain in twin pregnancies: a retrospective cohort study. Am J Clin Nutr. 2017;17(1):330

18. Wang Y, Mi J, Shan XY, Wang QJ, Ge KY. Is China facing an obesity epidemic and the consequences? The trends in obesity and chronic disease in China. International journal of obesity (2005). 2007;31(1):177-88.

19. Pettit KE, Lacoursiere DY, Schrimmer DB, Alblewi H, Moore TR, Ramos GA. The association of inadequate mid-pregnancy weight gain and preterm birth in twin pregnancies. J Perinatol. 2014;35(2):85-9.

20. Lal AK, Kominiarek MA. Weight gain in twin gestations: are the Institute of Medicine guidelines optimal for neonatal outcomes? J Perinatol. 2015;35(6):405-10
21. Gonzalez-Quintero VH, Kathiresan AS, Tudela FJ, Rhea D, Desch C, Istwan N. The association of gestational weight gain per institute of medicine guidelines and prepregnancy body mass index on outcomes of twin pregnancies. Am J Perinatol. 2012;29(6):435-40.

22. Fox NS, Rebarber A, Roman AS, Klauser CK, Peress D, Saltzman DH. Weight gain in twin pregnancies and adverse outcomes: examining the 2009 Institute of Medicine guidelines. Obstet Gynecol. 2010;116(1):100-6.

23. American College of Obstetricians and Gynecologists, Task Force on Hypertension in Pregnancy. Hypertension in pregnancy. Report of the American College of Obstetricians and Gynecologists' Task Force on Hypertension in Pregnancy. Obstet Gynecol. 2013;122(5):1122-31.

24. Zhang B, Cao Z, Zhang Y, Yao C, Xiong C, Zhang Y, Wang Y, Zhou A. Birthweight percentiles for twin birth neonates by gestational age in China. Sci Rep. 2016:6:31290.

25. Dai L, Deng C, Li Y, Yi L, Li X, Mu Y, Li Q, Yao Q, Wang Y. Population-based birth weight reference percentiles for Chinese twins. Ann Med. 2017;49(6):470-8.

26. Pécheux O, Garabedian C, Drumez E, Mizrahi S, Cordiez S, Deltombe S, Deruelle P. Maternal and neonatal outcomes according to gestational weight gain in twin pregnancies: are the Institute of Medicine guidelines associated with better outcomes? Eur J Obstet Gynecol Reprod Biol. 2019;234:190-4.

27. Ozcan T, Bacak SJ, Zozzaro-Smith P, Li D, Sagcan S, Seligman N, Glantz CJ. Assessing weight gain by the 2009 Institute of Medicine Guidelines and Perinatal Outcomes in twin pregnancy. Matern Child Health J. 2017;21(3):509-15

28. Shamshirsaz AA, Haeri S, Ravangard SF, Sangi-Haghpeykar H, Gandhi M, Ozhand A, Spiel M, Trout S, Sadowski A, Hussain N, et al. Perinatal outcomes based on the institute of medicine guidelines for weight gain in twin pregnancies. J Matern Fetal Neonatal Med. 2014;27(6):552-6.

29. Chen YW, Liu Y, Zhang YM, Hu RH, Qian ZM, Xian H, Vaughn MG, Liu MZ, Cao SY, Gan Y, et al. Gestational weight gain per pre-pregnancy body mass index and birth weight in twin pregnancies: a cohort study in Wuhan, China. Sci Rep. 2018:8(1):12496.

30. Wang L, Wen L, Zheng Y, Zhou W, Mei L, Li H, Tong C, Qi H, Baker PN. Association Between Gestational Weight Gain and Pregnancy Complications or Adverse Delivery Outcomes in Chinese Han Dichorionic Twin Pregnancies: Validation of the Institute of Medicine (IOM) 2009 Guidelines. Med Sci Monit. 2018(24):8342-7.

31. Hulman A, Woolcott C, Beyene J, Giglia L, Armson BA, Dodds L, Neupane B, McDonald SD, Kosinska-Kaczynska K, Szymusik I, et al. Observational study of associations between gestational weight gain and perinatal outcomes in dichorionic twin pregnancies. BMC Pregnancy Childbirth. 2017;138(1):94-9.

32. Kominiarek MA, Saade G, Mele L, Bailit J, Reddy UM, Wapner RJ, Varner MW, Thorp JM Jr, Caritis SN, Prasad M, et al. Association between gestational weight gain and perinatal outcomes. Obstet Gynecol. 2018;132(4):875-81.

\section{Publisher's Note}

Springer Nature remains neutral with regard to jurisdictional claims in published maps and institutional affiliations.

Ready to submit your research? Choose BMC and benefit from:

- fast, convenient online submission

- thorough peer review by experienced researchers in your field

- rapid publication on acceptance

- support for research data, including large and complex data types

- gold Open Access which fosters wider collaboration and increased citations

- maximum visibility for your research: over $100 \mathrm{M}$ website views per year

At BMC, research is always in progress.

Learn more biomedcentral.com/submissions 